\title{
Impaired translational response and increased protein kinase PKR expression in T cells from lupus patients
}

\author{
Annabelle Grolleau, ${ }^{1}$ Mariana J. Kaplan, ${ }^{2}$ Samir M. Hanash, ${ }^{3}$ \\ Laura Beretta, ${ }^{1,4}$ and Bruce Richardson ${ }^{2,5}$ \\ ${ }^{1}$ Institut National de la Santé et de la Recherche Médicale (INSERM), Unité 365, Institut Curie, Paris, France \\ ${ }^{2}$ Department of Internal Medicine, \\ ${ }^{3}$ Department of Pediatrics, and \\ ${ }^{4}$ Department of Microbiology and Immunology, University of Michigan, Ann Arbor, Michigan, USA \\ ${ }^{5}$ Department of Medicine, Veterans Affairs Medical Center, Ann Arbor, Michigan, USA \\ Address correspondence to: Laura Beretta, Department of Microbiology and Immunology, \\ University of Michigan, 1150 W. Medical Center Drive, 1510 MSRBI, Ann Arbor, Michigan 48109, USA. \\ Phone: (734) 615-5964; Fax: (734) 615-6150; E-mail: berettal@umich.edu.
}

Received for publication January 11, 2000, and accepted in revised form November 9, 2000.

\begin{abstract}
Activation of peripheral blood $\mathrm{T}$ cells results in a rapid and substantial rise in translation rates and proliferation, but proliferation in response to mitogen stimulation is impaired in systemic lupus erythematosus (SLE). We have investigated translation rates and initiation factor activities in $\mathrm{T}$ cells from SLE patients in response to activating signals. Activation by PMA plus ionomycin strongly increased protein synthesis in control $\mathrm{T}$ cells but not in $\mathrm{T}$ cells from SLE patients. The rate of protein synthesis is known to be strongly dependent on the activity of two eukaryotic translation initiation factors, eIF4E and eIF2 $\alpha$. We show that following stimulation, eIF4E expression and phosphorylation increased equivalently in control and SLE T cells. Expression of eIF4E interacting proteins - eIF4G, an inducer, and 4E-BP1 and 4E-BP2, two specific repressors of eIF4E function - and the phosphorylation level of 4E-BP1, were all identical in control and SLE T cells. In contrast, the protein kinase PKR, which is responsible for the phosphorylation and consequent inhibition of eIF2 $\alpha$ activity, was specifically overexpressed in activated SLE T cells, correlating with an increase in eIF2 $\alpha$ phosphorylation. Therefore, high expression of PKR and subsequent eIF2 $\alpha$ phosphorylation is likely responsible, at least in part, for impaired translational and proliferative responses to mitogens in $\mathrm{T}$ cells from SLE patients.
\end{abstract}

J. Clin. Invest. 106:1561-1568 (2000).

\section{Introduction}

Systemic lupus erythematosus (SLE) is an autoimmune disease characterized by disordered cellular immune responses leading to autoantibody production (1). To date no definitive mechanism leading to autoimmunity in SLE has been discovered. Impaired in vitro T-cell proliferation in response to mitogens and antigens is a fundamental immune defect that has long been known to occur in SLE. In addition, abnormalities of apoptotic cell death process and cytokine gene production may contribute to the pathogenesis of SLE (2-4).

The translation rate is an important determinant of cell proliferation, and numerous studies have demonstrated that cell proliferation is accompanied by increased rates of protein synthesis. Translation rates generally increase in response to treatment with growth factors, cytokines, hormones, and mitogens, and translational control is an important regulatory mechanism for growth-related genes and cytokine expression (5-7). A recent accumulation of evidence points to additional roles for translation initiation factors in the control of signal transduction and apoptosis (8-10). Most of the control of translation occurs at the level of initiation which entails the posi- tioning of the ribosome at the AUG initiation codon. There are two steps in the translational initiation pathway that are highly regulated: (a) the binding of the small ribosomal subunit to the $5^{\prime}$ end of the mRNA, mediated by eIF4E, and (b) the binding of the initiator tRNA to the small ribosomal subunit, mediated by eIF2 $(5,11)$. Cellular mRNAs contain a cap structure $\left[\mathrm{m} 7 \mathrm{G}\left(5^{\prime}\right) \mathrm{ppp}\left(5^{\prime}\right) \mathrm{N}\right.$; where $\mathrm{N}$ is any nucleotide] at their $5^{\prime}$ terminus (12). The initiation factor eIF4E is the cap-binding protein (13). eIF4E activity is regulated at different levels: (a) phosphorylation: the phosphorylated form of eIF4E binds to the cap structure $(14,15)$, (b) expression: it is the limiting factor in the translation process and its overexpression results in an increase of cell proliferation $(6,16)$, and (c) interaction: the dephosphorylated translational repressors 4E-BP1 and 4E-BP2 interact with eIF4E and inhibit the association of eIF4E with eIF4G, whereas the association of eIF4G with eIF4E strongly enhances the binding of the latter to $5^{\prime}$ mRNA cap structures (17-20). eIF2 binds GTP and the initiator Met-tRNA and transfers Met-tRNAi to the $40 \mathrm{~S}$ ribosomal subunit. Phosphorylation of the eIF $2 \alpha$-subunit prevents formation of the 
eIF2.GTP.Met-tRNAi complex and inhibits protein synthesis (21). The protein kinase PKR, an interferoninducible gene whose activity is regulated by doublestranded RNA, is responsible for eIF $2 \alpha$ phosphorylation $(22,23)$. In peripheral blood $\mathrm{T}$ cells, mitogenic activation results in a strong increase in translation rates concomitant with increased expression and/or phosphorylation of several translation initiation factors, including eIF4E and eIF2 $\alpha$ (24-27).

Therefore, given the importance of translational control of cell proliferation, of apoptotic response, and of the regulation of cytokine production, we investigated translation rates as well as eIF4E and eIF2 $\alpha$ activities in $\mathrm{T}$ cells from lupus patients.

\section{Methods}

Antibodies and other reagents. PMA, ionomycin, hydrocortisone and chloroquine were purchased from Sigma Chemical Co. (St. Louis, Missouri, USA). All cell culture medium and reagents were from GIBCO BRL (Grand Island, New York, USA). Antibodies against 4E-BP2 and eIF4G were generous gifts from N. Sonenberg (Department of Biochemistry, McGill University, Montréal, Canada). Antibodies against 4E-BP1, eIF4E, PKR, the phosphorylated form of eIF $2 \alpha$ and actin were purchased from TEBU (Le Peray-en-Yvelines, France), Interchim (Montluçon, France), Ribogene (Hayward, California, USA), Research Genetics (Huntsville, Alabama, USA) and ICN (Orsay, France), respectively.

Preparation of $T$ cells. Peripheral blood was obtained from healthy volunteer donors, patients with active and inactive lupus, and patients with rheumatoid arthritis (RA). The control population consisted of 20 healthy individuals ( $57 \%$ women and $43 \%$ men), ranging from 19 to 40 years old (mean 28 years). The lupus population consisted of 13 active lupus and 10 inactive lupus patients, ranging from 22 to 63 years old (mean 38 years). The RA population consisted of four patients, ranging from 33 to 69 years old (mean 50 years). Patients with lupus met criteria for lupus (28), and patients with RA met criteria for RA (29). Lupus disease activity was assessed by the Systemic Lupus Activity Measure (SLAM) (30) and by the Systemic Lupus Erythematosus Disease Activity Index (SLEDAI) (31). Lupus was considered inactive if the SLAM was less than or equal to 5 and the SLEDAI was less than or equal to 11 . The clinical parameters of these subjects are described in Table 1.

Mononuclear cells were isolated using Ficoll-Hypaque (Amersham Pharmacia Biotech, Uppsala, Sweden) density gradient centrifugation, and $\mathrm{T}$ cells were separated by rosetting with sheep erythrocytes (Colorado Serum Co., Denver, Colorado, USA). For this, mononuclear cells (20 $\times 10^{6}$ cells $/ \mathrm{ml}$ ) in RPMI 1640 plus $10 \%$ FBS were added to an equal volume of $5 \%$ red blood cells (RBCs) suspended in RPMI 1640 plus 10\% FBS and centrifuged at $180 \mathrm{~g}$ for 5 minutes. Following overnight incubation at $4^{\circ} \mathrm{C}$, the cells were centrifuged on a Ficoll-Hypaque gradient (Amersham Pharmacia Biotech). The cell pellet contain- ing the T cells was harvested, and the RBCs were lysed by incubation in $0.33 \%$ Tris-ammonium chloride for 2 minutes at $37^{\circ} \mathrm{C}$. The $\mathrm{T}$ cells obtained were then washed and resuspended in RPMI 1640 medium supplemented with $10 \%$ FCS, at a density of $2 \times 10^{5}$ cells $/ \mathrm{ml}$. When specified, PMA was used at $10 \mathrm{ng} / \mathrm{ml}$ and ionomycin at $400 \mathrm{ng} / \mathrm{ml}$. When indicated, hydrocortisone and chloroquine were added to the culture medium at various ranges of concentration as previously described $(32,33)$.

Transfection and cell sorting assays. Jurkat cells were cultured in RPMI 1640 supplemented with 10\% FCS. Cells $\left(1 \times 10^{7}\right)$ were washed with ice-cold PBS and preincubated for 1 minute on ice with $2 \mu \mathrm{g}$ of pEGFP vector encoding the enhanced green fluorescence protein (EGFP) (CLONTECH Laboratories Inc., Palo Alto, California, USA) and $10 \mu \mathrm{g}$ of $\mathrm{pEF}$ or $\mathrm{pEF}-\mathrm{PKR}$ plasmids (generous gifts from A. Koromilas, Lady Davis Institute, Montréal, Canada), in 0.4-cm gap sterile disposable electroporation cuvettes. Cotransfections were carried out by electroporation with a Gene Pulser (Bio-Rad Laboratories Inc., Hercules, California, USA) at $270 \mathrm{~V}$ and 960 microfarads. After electroporation, cells were immediately resuspended in fresh complete medium and cultured for 24 hours before cell sorting for EGFP fluorescence by flow cytometry. Ninety-five percent of selected cells were efficiently transfected.

\section{Table 1}

Clinical and demographic characteristics of SLE and RA patients

\begin{tabular}{|c|c|c|c|c|c|}
\hline \multicolumn{6}{|l|}{ Lupus } \\
\hline 1 & 37 & $\mathrm{~F}$ & 18 & 28 & Plaq, pred mod, Cycl \\
\hline 2 & 62 & M & 17 & 15 & None \\
\hline 3 & 25 & $\mathrm{~F}$ & 14 & 18 & Pred high \\
\hline 4 & 45 & $\mathrm{~F}$ & 10 & 16 & Pred high \\
\hline 5 & 34 & $\mathrm{~F}$ & 10 & 16 & Plaq, pred low \\
\hline 6 & 37 & $\mathrm{~F}$ & 18 & 13 & Plaq, pred mod, aza \\
\hline 7 & 30 & $\mathrm{~F}$ & 9 & 12 & Pred high, Cycl \\
\hline 8 & 51 & $\mathrm{~F}$ & 8 & 16 & Pred high \\
\hline 9 & 42 & $\mathrm{~F}$ & 20 & 36 & Plaq, pred high \\
\hline 10 & 30 & $\mathrm{~F}$ & 19 & 22 & Plaq, MTX, pred mod \\
\hline 11 & 22 & $\mathrm{~F}$ & 18 & 37 & Plaq, pred high \\
\hline 12 & 47 & $\mathrm{~F}$ & 12 & 12 & Plaq, pred low \\
\hline 13 & 26 & $\mathrm{~F}$ & 18 & 20 & Mycoph, Cycl, pred hig \\
\hline 14 & 34 & $\mathrm{~F}$ & 0 & 2 & Plaq, pred low \\
\hline 15 & 37 & $\mathrm{~F}$ & 3 & 7 & Plaq, pred mod, aza \\
\hline 16 & 34 & $\mathrm{~F}$ & 4 & 7 & Plaq, pred low \\
\hline 17 & 28 & M & 4 & 2 & Plaq, pred low, aza \\
\hline 18 & 30 & $\mathrm{~F}$ & 3 & 0 & Plaq, pred low \\
\hline 19 & 34 & $\mathrm{~F}$ & 3 & 2 & Plaq, pred low, aza \\
\hline 20 & 39 & $\mathrm{~F}$ & 2 & 0 & Plaq, pred low \\
\hline 21 & 52 & $\mathrm{~F}$ & 1 & 0 & Plaq, pred low \\
\hline 22 & 63 & $\mathrm{~F}$ & 0 & 0 & Plaq \\
\hline 23 & 52 & $\mathrm{~F}$ & 2 & 6 & None \\
\hline \multicolumn{6}{|c|}{ Rheumatoid arthritis } \\
\hline Patient & Age & Gender & Activity & & Medications \\
\hline 1 & 69 & M & Inactive & & Plaq, pred low, MTX \\
\hline 2 & 36 & M & Active & & Plaq, pred low \\
\hline 3 & 45 & $\mathrm{~F}$ & Inactive & & Plaq, pred low, MTX \\
\hline & 50 & $\mathrm{~F}$ & Inactive & & Plaq, MTX, sulf, etan \\
\hline
\end{tabular}

Pred low, < $0.5 \mathrm{mg} / \mathrm{kg} / \mathrm{d}$; pred mod, $=0.5-1 \mathrm{mg} / \mathrm{kg} / \mathrm{d}$; pred high, $>1$ $\mathrm{mg} / \mathrm{kg} / \mathrm{d}$; Pred, Prednisone; Plaq, Hydroxychloroquine $200 \mathrm{mg}$ twice a day; Cycl, Cyclophosphamide; aza, azathioprine; MTX, Methotrexate; Mycoph, Mycophenolate; sulf, sulfasalazine; etan, etanercept. 
Metabolic labeling. Cells were cultured in 24-well culture plates at $2.5 \times 10^{5}$ cells/well in a total volume of 1 $\mathrm{ml}$ of RPMI 1640 medium containing $10 \%$ FBS. After 1 hour of incubation, stimulation of cells was performed with either medium alone or with PMA plus ionomycin. At the indicated times, cells were washed and incubated in $1 \mathrm{ml}$ of methionine-free medium containing $\left[{ }^{35} \mathrm{~S}\right]$ methionine $(25 \mu \mathrm{Ci})$. After 2 hours of incubation at $37^{\circ} \mathrm{C}$, cells were harvested, washed, and lysed in buffer containing $0.5 \% \mathrm{NP}-40,140 \mathrm{mM} \mathrm{NaCl}$, and 30 $\mathrm{mM}$ Tris- $\mathrm{HCl}$ ( $\mathrm{pH} 7.5$ ). The radioactivity incorporated into trichloroacetic acid-precipitable (TCA-precipitable) material was measured.

Two-dimensional polyacrylamide gel electrophoresis. The procedure followed was as previously described (34, $35)$. Cell pellets were solubilized in lysis buffer containing $9.5 \mathrm{M}$ urea, 2\% NP-40, 2\% of 2-mercaptoethanol, and $0.2 \mathrm{mM}$ of PMSF in distilled deionized water. After lysis, $30-\mu \mathrm{l}$ aliquots containing $5 \times 10^{6}$ cells were applied onto iso-focusing gels. Isoelectric focusing was carried out, using $\mathrm{pH} 4-8$ carrier ampholytes, at $1200 \mathrm{~V}$ for 16 hours and $1500 \mathrm{~V}$ for an additional 2 hours. For the second dimension separation, an acrylamide gradient of $11.4-14.0 \mathrm{~g} / \mathrm{dl}$ was used. Proteins were transferred to Immobilon-P PVDF membrane (Millipore Corp., Bedford, Massachusetts, USA) and blotted with an anti-eIF4E antiserum.

SDS-PAGE and Western blotting. Cells $\left(3 \times 10^{6}\right)$ were dissolved in Laemmli sample buffer and the samples were loaded onto an SDS polyacrylamide gel. Proteins were transferred onto a $0.22 \mu \mathrm{m}$ nitrocellulose membrane (Schleicher \& Schuell, Dasel, Germany), which was blocked in 5\% milk for 2 hours, followed by incubation for 2 hours with specific antiserum in $10 \mathrm{mM}$ Tris- $\mathrm{HCl}$, pH 8.0 buffer containing $150 \mathrm{mM} \mathrm{NaCl}$. The membrane was then incubated for 2 hours with horseradish peroxidase-labeled conjugate $\mathrm{Ab}$ at a dilution of $1 / 2000$. Immunodetection was realized by enhanced chemoluminescence (ECL) reagents and autoradiography.

$R T$-PCR. Total RNA was isolated from 2.5-6 $\times 10^{6}$ normal or active lupus $T$ cells, using TriZol reagents (GIBCO BRL). Single-stranded cDNA was synthesized from total RNA using Moloney's murine leukemia virus reverse transcriptase and random hexamers as primers. Preliminary experiments were performed to determine the conditions in which cDNAs were amplified in the linear region of the PCR reaction curve. The reaction mixture was composed of 1 or $4 \mu \mathrm{l}$ of cDNA template (1/50 dilution) obtained from $1 \mu \mathrm{g}$ of extracted RNA, $25 \mathrm{pmol}$ of primers, $25 \mathrm{nmol}$ of each dNTP, $2.5 \mathrm{U}$ of Taq DNA polymerase, and $10 \mu \mathrm{l}$ of $10 \times$ PCR buffer in a final volume of $50 \mu \mathrm{l}$. PCR amplification conditions were as follows: denaturation at $94^{\circ} \mathrm{C}$ for 5 minutes, amplification during 30 cycles composed of denaturation at $94^{\circ} \mathrm{C}$ for 30 seconds, annealing at $57^{\circ} \mathrm{C}$ for 30 seconds, and extension at $72^{\circ} \mathrm{C}$ for 1 minute, followed by a final extension at $72^{\circ} \mathrm{C}$ for 10 minutes. The nucleotide sequence of primers used are $5^{\prime}$ -
GCCTTTTCATCCAAATGGAATTC-3' and 5'-GAAATCTGTTCTGGGCTCATG-3' for PKR (36) and 5'-ATCATGTTTGAGACCTTCAA-3' and 5'-TTGCGCTCAGGAGGAGCAAT- $3^{\prime}$ for $\beta$-actin cDNA sequences. The expression level for each transcript was evaluated after ethidium bromide staining. Each PCR reaction was reproduced three times by sample.

Statistical analysis. The significance of differences between groups was determined using analysis of variance (ANOVA), with the level of significance set at $P<$ 0.05. Regression analysis was performed with Systat software (SPSS Science, Chicago, Illinois, USA).

\section{Results}

Protein synthesis rates in unstimulated and stimulated lupus T cells. We analyzed protein synthesis rates during activation of $\mathrm{T}$ cells from controls and lupus patients. $\mathrm{T}$ cells were isolated from eight healthy controls, eight patients with active lupus (patients 1-8), and six patients with inactive lupus (patients 14, 15, 18, and 20-22), and were similarly stimulated by PMA plus ionomycin. The translation rate was determined by metabolic labeling of the cells with $\left[{ }^{35} \mathrm{~S}\right]$ methionine, and incorporation rates were measured 24 hours after stimulation (Figure 1a). The relative basal rates of protein synthesis in lupus $\mathrm{T}$ cells as compared with control T cells were approximately similar. Treatment of control T cells with PMA plus ionomycin for 24 hours resulted in an $92 \pm 25$ fold increase (mean \pm SEM) in protein synthesis as expected. The same treatment resulted in $5 \pm 2$ or $23 \pm 9$ fold increase (mean \pm SEM) in protein synthesis, in T cells from lupus with active disease or inactive disease, respec-

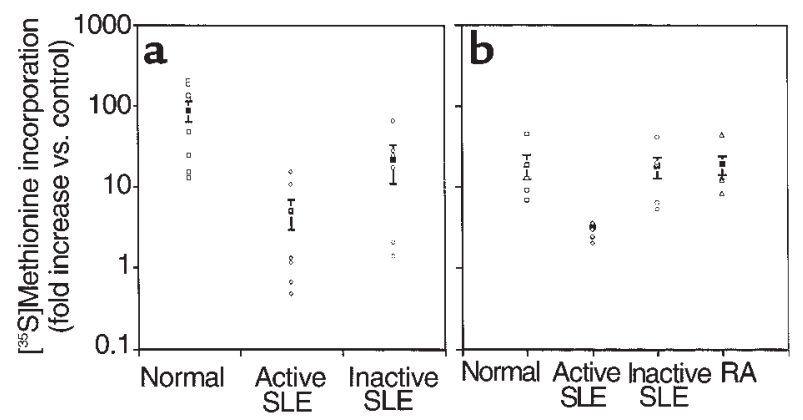

\section{Figure 1}

Protein synthesis in normal and lupus T cells. (a) T cells from eight healthy controls, seven patients with active lupus, and six patients with inactive lupus were treated with PMA $(10 \mathrm{ng} / \mathrm{ml})$ and ionomycin (400 ng/ml) for 24 hours. (b) T cells from five healthy controls, five patients with active lupus, five patients with inactive lupus, and four patients with RA were treated with PMA $(10 \mathrm{ng} / \mathrm{ml})$ and ionomycin $(400 \mathrm{ng} / \mathrm{ml})$ for 8 hours. Following treatment, cells were preincubated for 1 hour in methionine-free medium, then $\left[{ }^{35} \mathrm{~S}\right]$ methionine $(25 \mu \mathrm{Ci})$ was added for 2 hours. The radioactivity incorporated into TCA-precipitable material was measured. Incorporation of $\left.{ }^{35} \mathrm{~S}\right]$ methionine is expressed as fold increase as compared with unstimulated cells. Each point represents a single subject. The symbols with error bars represent the mean \pm SEM of the group. 

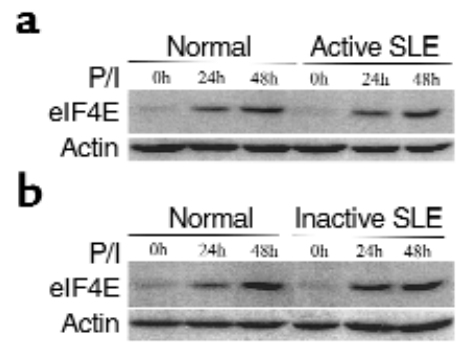

\section{Figure 2}

Expression of elF4E in active (a) and inactive (b) lupus T cells. $3 \times 10^{6}$ cells untreated or treated with PMA plus ionomycin $(\mathrm{P} / \mathrm{I})$, were dissolved in Laemmli sample buffer, and total protein extracts were loaded onto a $12 \%$ SDS polyacrylamide gel. Proteins were analyzed by Western blotting, using monoclonal anti-elF4E, followed by monoclonal anti-actin antibodies.

tively ( $P=0.014$ lupus vs. normal by ANOVA). Similar results were obtained following 8 hours of treatment (Figure 1b), as treatment of control T cells with PMA plus ionomycin for 8 hours resulted in a $19 \pm 6$ fold increase (mean \pm SEM) in protein synthesis and in $3 \pm$ 0.3 or $18 \pm 5$ fold increase (mean \pm SEM), in T cells from lupus with active disease or inactive disease, respectively. The defect of protein synthesis induction is therefore an early event in the impaired response of mitogen-stimulated lupus $\mathrm{T}$ cells. The defect in protein synthesis following stimulation of $\mathrm{T}$ cells from patients with lupus was specific to lupus, as protein synthesis induction was normal ( $19 \pm 5$ fold increase) after 8 hours of PMA plus ionomycin treatment in four patients with RA (patients 24-27) (Figure 1b). In addition, this defect could not be attributed to corticosteroids and cyclophosphamide because some patients with active or inactive lupus (patients 2 and 23) were not receiving these drugs at the time of the experiments, yet remained hyporesponsive.

eIF4E expression and phosphorylation. To study the mechanisms involved in the defect of protein synthesis induction observed in stimulated lupus $\mathrm{T}$ cells, the expression and phosphorylation of eIF4E, known to positively correlate with cell growth (6), were examined. We analyzed eIF4E expression and phosphorylation in $\mathrm{T}$ cells from five controls, three active lupus patients (nos. 1, 4, and 7), and two inactive lupus patients (nos. 14 and 23). At 24 hours and 48 hours of PMA plus ionomycin treatment, eIF4E expression was increased in control and lupus $T$ cells to the same extent, and no differences in the amount of total protein was observed between the groups (Figure 2).

To examine eIF4E phosphorylation, cells treated with PMA plus ionomycin for 1 hour were lysed in urea buffer, and proteins were separated by two-dimensional polyacrylamide gel electrophoresis (2D-PAGE). The eIF4E isoforms on the 2D-gels were identified by immunoblotting using an antibody against eIF4E as reported (35). eIF4E is resolved by 2D-PAGE into two isoforms, a nonphosphorylated $(\mathrm{pI}=6.3)$ designated eIF4E and a phosphorylated form $(\mathrm{pI}=5.9)$ designated
eIF4E (P). In control T cells as well as in all lupus T cells tested, the amount of the phosphorylated form, eIF4E $(\mathrm{P})$, increased following PMA plus ionomycin treatment as shown for one active and one inactive lupus patient in Figure 3. Therefore, induction of eIF4E phosphorylation is normal in lupus $\mathrm{T}$ cells.

Expression of eIF4E interacting proteins in lupus $T$ cells. eIF4E function is also regulated by its association with other proteins, including two repressors of its activity, 4E-BP1 and 4E-BP2, and eIF4G, which enhances eIF4E function. We examined the expression of 4E-BP1, 4EBP2, and eIF4G in T cells from six controls, four active (patients 1, 4, 5, and 8), and four inactive (patients 17, 18, 19, and 22) lupus patients. 4E-BP1 and 4E-BP2 protein expression was identical in lupus $\mathrm{T}$ cells as compared with control $\mathrm{T}$ cells. Figure 4 shows a typical Western blot. Phosphorylation of 4E-BP1 strongly regulates eIF4E function and translation rates, and 4E-BP1 is dephosphorylated by the immunosuppressant rapamycin (37). Three isoforms of 4E-BP1 (indicated by the arrows in Figure 4) can be detected following immunoblotting of extracts from most human cells, and these isoforms represent various phosphorylation states of 4E-BP1, the fastest migrating electrophoretic isoform corresponding to the unphosphorylated 4E-BP1 $(17,18$, 37). In $\mathrm{T}$ cells, $4 \mathrm{E}-\mathrm{BP} 1$ is mostly dephosphorylated, and no significant modification was observed in 4E-BP1 phosphorylation during treatment of the control or the lupus T cells with PMA plus ionomycin.

eIF4G, which has recently been described to be degraded as part of the Fas-induced apoptotic response in lymphoma cell lines (38), is also expressed to equal amount in control and lupus $T$ cells and remains intact following activation of lupus $\mathrm{T}$ cells (Figure 5). We conclude that in lupus $\mathrm{T}$ cells, eIF4E remains functional.

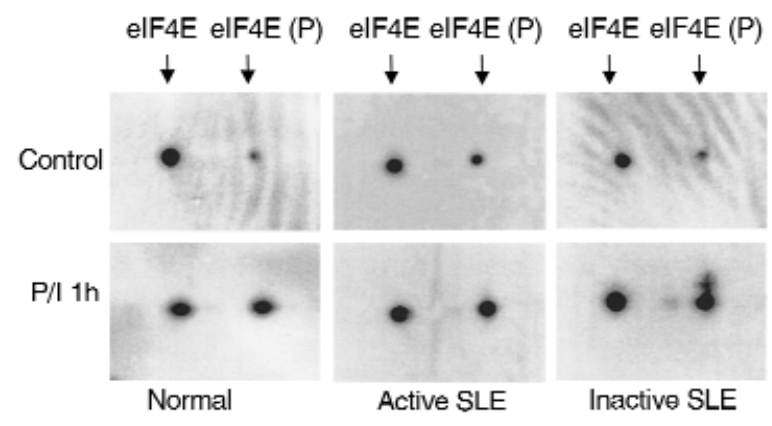

Figure 3

2D-PAGE analysis of elF4E isoforms from lupus and normal T cells. Resting or PMA plus ionomycin-treated normal and lupus T cells were solubilized by a standard lysis buffer as described in Methods. Proteins were resolved by 2D-PAGE using $\mathrm{pH}$ 4-8 carrier ampholytes for the first dimension and $11-14 \%$ polyacrylamide gradient for the second dimension. The positions of elF4E isoforms were identified by immunoblotting analysis using a monoclonal antibody to elF4E, and the blown sections displaying the elF4E isoforms are shown. Arrows marked elF4E and elF4E (P) indicate the positions of the nonphosphorylated and phosphorylated forms of elF4E, respectively. 
a

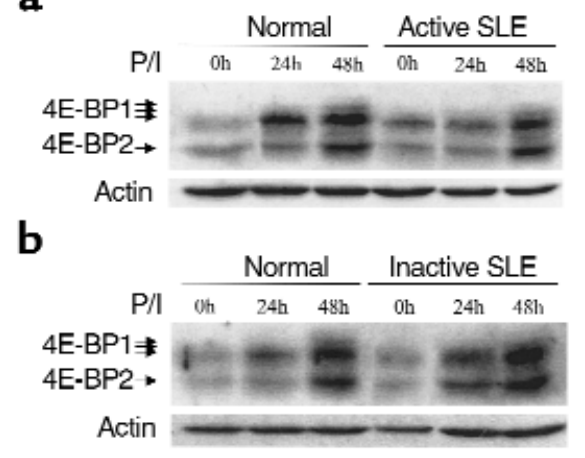

Figure 4

Expression of 4E-BPs in active (a) and inactive (b) lupus T cells. $3 \times$ $10^{6}$ cells untreated or treated with PMA plus ionomycin for 24 and 48 hours were lysed, and total protein extracts were analyzed by Western blotting, using rabbit anti-4E-BP1 (1:500), rabbit anti-4EBP2 (1:1000) Ab's, followed by monoclonal anti-actin.

Expression of PKR in lupus T cells. Expression of PKR was then analyzed in $\mathrm{T}$ cells isolated from nine healthy controls, six active (patients 1,3 , and 5-8), and three inactive (patients 16, 20, and 22) lupus patients. We observed a marked change in PKR expression following activation of active lupus T cells as shown for three patients in Figure 6. In control $T$ cells, PKR is slightly induced following PMA plus ionomycin treatment $(2 \pm 0.5$ fold increase, mean \pm SEM $)$. However, PMA plus ionomycin treatment caused significantly more PKR protein expression in $\mathrm{T}$ cells from active lupus patients relative to healthy controls $(9 \pm 3$ fold increase, mean \pm SEM $)(P=0.027$ by ANOVA). In addition, the induction of PKR was more rapid in active lupus $\mathrm{T}$ cells as upregulation of PKR following activation of lupus $T$ cells occurred as early as after 4 hours of treatment (Figure 6c) and the maximal level of PKR was reached after 8 hours of treatment. This high expression of PKR was observed in $\mathrm{T}$ cells from all six active lupus patients analyzed and in $\mathrm{T}$ cells from one out of three inactive lupus patients. Interestingly, the latter inactive lupus patient presented a concomitant lack of induction of protein synthesis following activation. The two inactive lupus patients for which PKR expression was normal did demonstrate an increase in protein synthesis following PMA plus ionomycin treatment.

In order to characterize the molecular basis of PKR overexpression in SLE T cells, RT-PCR amplification of PKR gene transcript was first undertaken. Expression of PKR mRNA was analyzed in T cells isolated from eight healthy controls and seven active lupus patients (patients 2, 7, and 9-13), untreated or treated with PMA plus ionomycin for four and eight hours. We observed a marked decrease in PKR mRNA expression following activation of normal $\mathrm{T}$ cells as shown for three healthy controls in Figure 7 (left panel). Surprisingly, in active lupus $T$ cells, PKR mRNA expression was also markedly decreased following PMA plus ion-

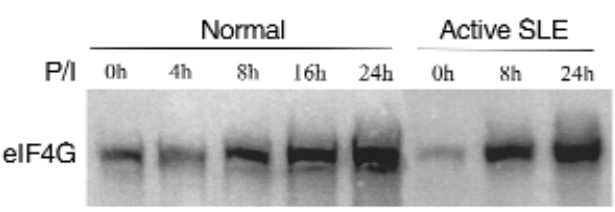

\section{Figure 5}

Expression of elF4G protein in lupus T cells. $3 \times 10^{6}$ cells were dissolved in Laemmli sample buffer and total protein extracts were loaded onto a $6 \%$ SDS polyacrylamide gel. Proteins were analyzed by Western blotting, using a monoclonal anti-elF4G antibody (1:500).

omycin treatment, as shown for three patients in Figure 7 (right panel). Therefore, overexpression of PKR in lupus $\mathrm{T}$ cells is most likely due to differential posttranscriptional regulation of the PKR gene.

eIF2 $\alpha$ phosphorylation in lupus T cells. To demonstrate that the PKR form overexpressed in lupus $\mathrm{T}$ cells is active, we assessed the phosphorylation state of eIF $2 \alpha$ in the same samples previously analyzed for PKR expression, by Western blotting using antibodies specific to phosphorylated eIF $2 \alpha$. As previously described (24), a decrease in eIF $2 \alpha$ phosphorylation was observed during the first 8 hours of activation of normal $T$ cells (Figure 8). In contrast, in active SLE patients, a marked increase in eIF $2 \alpha$ phosphorylation was observed following PMA plus ionomycin treatment (Figure 8). This increase in eIF $2 \alpha$ phosphorylation was not due to an increase in eIF $2 \alpha$ expression, as following 8 hours of stimulation of SLE T cells, there was no modification of eIF $2 \alpha$ expression (ref. 27 and data not shown). Furthermore, the kinetics of induction of eIF $2 \alpha$ phosphorylation and PKR expression were similar.

Overexpression of PKR and increase in eIF $2 \alpha$ phosphorylation were specific to lupus, as PKR expression

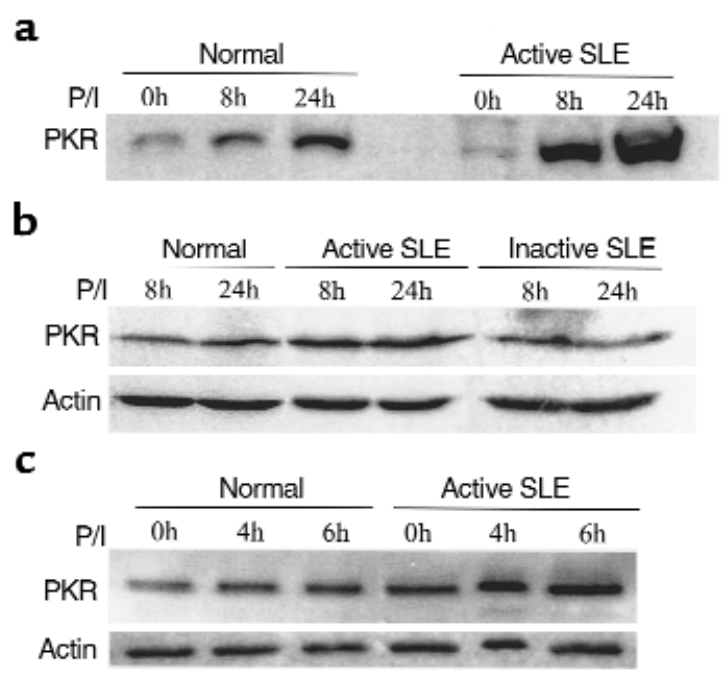

Figure 6

Expression of PKR protein in active $(\mathbf{a}, \mathbf{b}, \mathbf{c})$ and inactive (b) lupus $\mathrm{T}$ cells. $3 \times 10^{6}$ cells were dissolved in Laemmli sample buffer and analysed by SDS-PAGE and Western blotting, using a monoclonal antiPKR antibody. (c) Kinetic of induction of PKR in active lupus T cells. 


\section{Figure 7}

Expression of PKR mRNA in lupus T cells. Total RNA $(1 \mu \mathrm{g})$ from normal and active lupus $T$ cells, untreated or treated for 4 hours and 8 hours with PMA plus ionomycin, was reverse transcribed and PCR amplification was performed for PKR and actin genes as described in Methods. The products were analyzed on a $2 \%$ agarose gel, visualized by ethidium bromide staining. The size of the PCR product for PKR and actin are $290 \mathrm{bp}$ and $644 \mathrm{bp}$, respectively. Lane 0 represents the negative control which was the product of PCR where RNA was omitted.

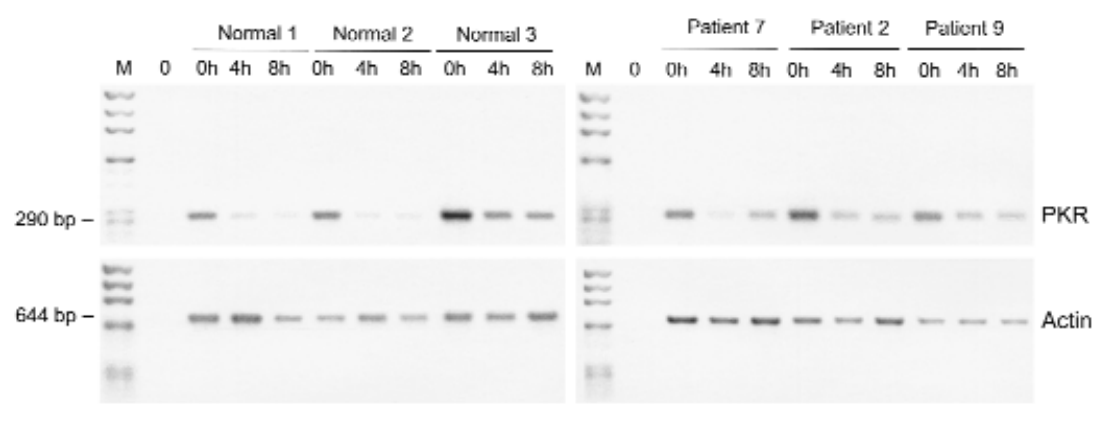

and eIF $2 \alpha$ phosphorylation were normal in four patients with RA as shown in Figure 9, a and b. The overexpression of PKR and the induction of eIF $2 \alpha$ phosphorylation, following stimulation of $\mathrm{T}$ cells from patients with active lupus, could not be attributed to corticosteroids and cyclophosphamide because some patients were not receiving these drugs at the time of the experiments, yet remained hyporesponsive. Furthermore, simultaneous treatment of normal T cells with PMA plus ionomycin and with hydrocortisone $(1-100 \mu \mathrm{M})$ or chloroquine $(10-100$ $\mu \mathrm{M})$ did not increase PKR expression, or eIF $2 \alpha$ phosphorylation (Figure 9c) in vitro.

Effect of PKR overexpression in T cells. Even though it has been demonstrated in many cell types that overexpression of PKR leads to an inhibition of protein synthesis, no such experiment has been reported so far in T cells. Therefore, we transiently overexpressed PKR in Jurkat $\mathrm{T}$ cells and measured protein synthesis rates in these cells. For this purpose, we cotransfected the pEGFP vector encoding the enhanced green fluorescence protein with the expression plasmid pEFPKR or with the empty vector pEF. Because of the low transfection efficiency (10-15\%), we selected cells expressing EGFP by flow cytometry. By Western blotting we confirmed that PKR was indeed overexpressed in the selected cells (Figure 10a). The translation rate was determined by metabolic labeling of the cells with $\left[{ }^{35} \mathrm{~S}\right]$ methionine and incorporation rates were measured 31 and 37 hours after transfection. We observed a strong inhibition of translation rate in cells overexpressing PKR as compared with control cells (Figure

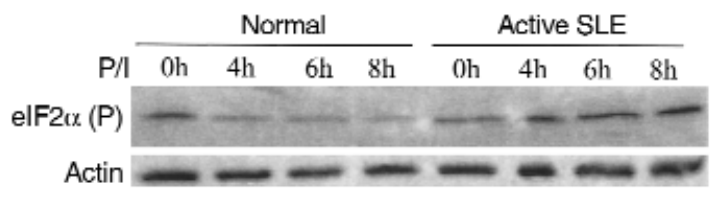

\section{Figure 8}

Phosphorylation of elF $2 \alpha$ in active lupus T cells. T cells were treated with PMA plus ionomycin for various time periods as indicated. Cell extracts were prepared and analysed by SDS-PAGE and Western blotting using a specific antibody against the phosphorylated form of elF $2 \alpha$. 10b). An increase in apoptosis was observed in PKR overexpressing cells, 48 hours post-transfection but not before (data not shown).

Therefore, it is likely that the reduced protein synthesis rates observed in lupus $T$ cells are accounted for in part by the overexpression of PKR and subsequent increased phosphorylation state of eIF $2 \alpha$, and that these defects might be common to a majority of lupus $\mathrm{T}$ cells, and participate in the impaired proliferative response of lupus $\mathrm{T}$ cells to mitogens.

\section{Discussion}

The translation rate is an important determinant of cell proliferation, and recently, close to $20 \%$ of the genes expressed in $\mathrm{T}$ cells have been shown to be translationally regulated during $\mathrm{T}$ cell activation (39). Because $T$ cells from patients with active lupus are relatively anergic (2-4), it was interesting to investigate translation rates in these cells. Our results show a defect of induction of translation rates in stimulated lupus $\mathrm{T}$ cells. We previously reported reduced trans-

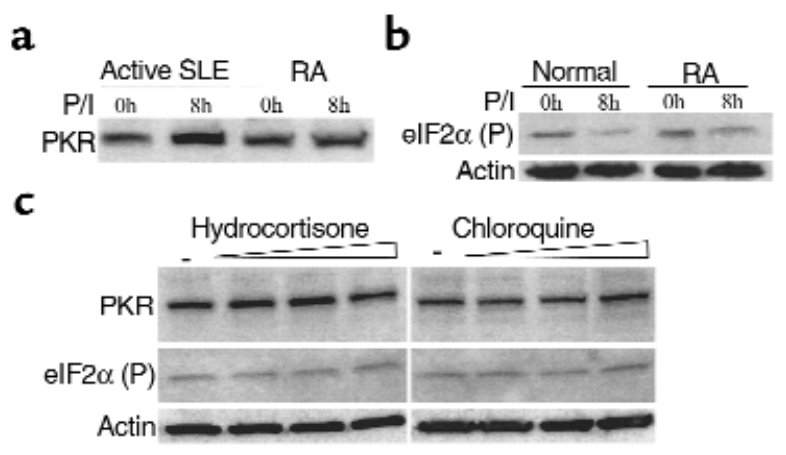

Figure 9

Specificity of PKR overexpression and elF $2 \alpha$ phosphorylation in lupus T cells. $3 \times 10^{6} \mathrm{~T}$ cells from a control, an active lupus patient, and an RA patient were treated with medium alone or with PMA plus ionomycin for 8 hours. Cells were then dissolved in Laemmli sample buffer and analysed by Western blotting using an anti-PKR (a) or an anti-phosphorylated elF $2 \alpha\left(\right.$ b) antibody. (c) T cells $\left(3 \times 10^{6}\right)$ isolated from a healthy control were treated with PMA plus ionomycin in absence (-) or in presence of increasing concentration of hydrocortisone $(1,10$, and $100 \mu \mathrm{M})$ or chloroquine $(10,50$ and $100 \mu \mathrm{M})$. Cells were harvested and analysed by SDS-PAGE and by Western blotting using anti-PKR and anti-phosphorylated elF $2 \alpha$ antibodies. 


\section{Figure 10}

PKR overexpression in Jurkat T cells. $1 \times 10^{7}$ Jurkat $T$ cells were cotransfected with pEGFP and either pEF-PKR or pEF, and 24 hours after transfection, cells expressing EGFP were selected as described in Methods. (a) Western-blotting analysis using an anti-PKR antibody. (b) $\left[{ }^{35} \mathrm{~S}\right]$ methionine incorporated into TCA-precipitable was measured after labeling of the cells, 31 and 37 hours after transfection.

lation rates in human immature thymocytes as well as in $\mathrm{T}$ cells treated with the immunosuppressant rapamycin $(35,37)$. In human immature double-positive $\mathrm{CD}^{+} \mathrm{CD}^{+}$thymocytes, which undergo apoptosis in response to activation, we showed that eIF4E is dephosphorylated and the expression of the repressor 4E-BP2 is high (35). Rapamycin treatment leads to 4EBP1 dephosphorylation and consequent sequestration of eIF4E and inhibition of translation initiation (37). In contrast, in lupus $T$ cells, our results suggest that eIF4E remains functional, and we observed a drastic change in PKR expression following activation of lupus $T$ cells. This high expression of PKR was observed in all active lupus $\mathrm{T}$ cells analyzed and in some cases of inactive lupus. Interestingly, these latter inactive lupus presented a concomitant lack of induction of protein synthesis following activation. Furthermore, upregulation of PKR following activation of lupus $\mathrm{T}$ cells occurred as early as after 4 hours of treatment and correlated with an increase in eIF $2 \alpha$ phosphorylation. PKR strongly regulates cell growth (23). Overexpression of PKR in mouse (40) and yeast cells (41) results in severe inhibition of growth, accompanied by increased eIF $2 \alpha$ phosphorylation, and we have now confirmed that overexpressing PKR inhibits protein synthesis in human $\mathrm{T}$ cells. Therefore, it is likely that the lack of proliferation observed in activated lupus $\mathrm{T}$ cells reflects in part a decreased activity of the translational machinery via components such as PKR and eIF2 $\alpha$.

An accumulation of evidence points to additional roles for PKR and eIF2 $\alpha$ in the control of signal transduction and apoptosis (42-44). The inducible expression of wild-type PKR activates apoptosis $(45,46)$, and PKR has been implicated as a general transducer of apoptosis in response to a variety of different stimuli (45, 47-50). Cells overexpressing PKR become extremely sensitive to dsRNA and TNF- $\alpha$ induced apoptosis (51). Furthermore, PKR overexpression results in a strong induction of Fas and Bax protein levels, due to posttranscriptional as well as transcriptional regulation of these two genes $(43,46)$. This is of particular interest as apoptosis after $\mathrm{T}$ cell activation in vitro is increased in SLE patients, and apoptosis is actively induced through the Fas pathway. SLE T cells express on their surface significantly higher amounts of Fas ligand compared with controls, and stimulation of the cells leads to a further, high increase in surface membrane Fas ligand expression (52-55). Therefore, PKR overexpression could account for the high apoptotic
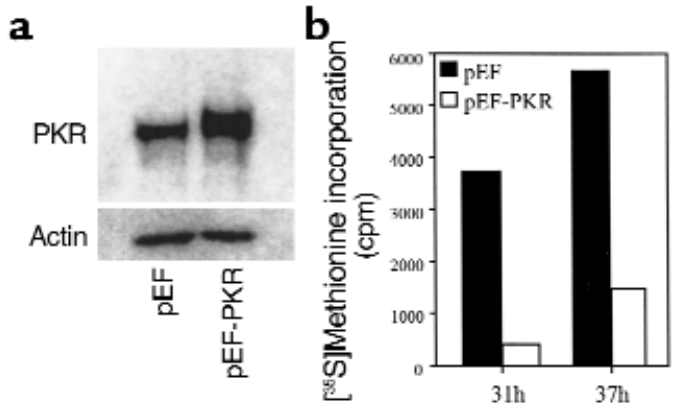

rates as well as for the Fas upregulation observed in lymphocytes from patients with SLE.

The basis for PKR overexpression in lupus T cells is currently under investigation. We showed that whereas PKR mRNA expression was decreased in response to activation in lupus $T$ cells, $\mathrm{PKR}$ protein expression was strongly increased. In normal $T$ cells, activation also resulted in a decrease in PKR mRNA expression, while PKR protein expression was unchanged or slightly increased. Therefore, posttranscriptional regulation of PKR may be an important mechanism involved in the control of PKR gene expression, dysregulated in lupus $\mathrm{T}$ cells.

Translational control has been identified as an important regulatory mechanism for many gene products involved in regulation of proliferation and for cytokines (56-59). Therefore, it would also be of great interest to determine the existence of specific genes whose translation may be regulated specifically or predominantly by PKR and eIF $2 \alpha$ and that may be affected in SLE.

In summary, our results suggest that abnormally increased PKR expression may directly contribute to the development of lupus by modifying T-cell gene expression and signaling. Interestingly, upregulation of PKR impairs cell functions identical to the biochemical abnormalities that are exhibited by lupus immune cells, including cell proliferation, Fas-dependent apoptosis, cytokine gene expression, and signaling. The determination of the mechanisms causing the increase in PKR expression and the identification of target mRNAs highly dependent on PKR and eIF $2 \alpha$ activities will yield data critical for addressing many unanswered questions about activation and apoptosis in lupus $\mathrm{T}$ cells and will be the subject of future studies.

\section{Acknowledgments}

The authors would like to thank Raymond Yung for helpful discussions, Nahum Sonenberg for providing antibodies against 4E-BP2 and eIF4G, and Donna Ray for her assistance. This work was supported by INSERM; Public Health Service grants AR42525, AG014783, and AI42753; and a Veterans Affairs Merit Review grant. A. Grolleau was supported by a fellowship from the French Ministry of Research.

\footnotetext{
1. Kotzin, B.L. 1996. Systemic lupus erythematosus. Cell. 85:303-306.

2. Dayal, A.K., and Kammer, G.M. 1996. The T cell enigma in lupus. Arthritis Rheum. 39:23-33.
} 
3. Liossis, S.N., Vassilopoulos, D., Kovacs, B., and Tsokos, G.C. 1997. Immune cell biochemical abnormalities in systemic lupus erythematosus. Clin. Exp. Rheumatol. 15:677-684.

4. Cohen, P.L. 1993. T- and B-cell abnormalities in systemic lupus. J. Invest. Dermatol. 100(Suppl.):69S-72S.

5. Pain, V.M. 1996. Initiation of protein synthesis in eukaryotic cells. Eur. J. Biochem. 236:747-771.

6. Sonenberg, N. 1996. mRNA 5' cap-binding protein eIF4E and control of cell growth. In Translational control. J.W.B. Hershey, M.B. Mathews, and N. Sonenberg, editors. Cold Spring Harbor Laboratory Press. Cold Spring Harbor, New York, USA. 245-269.

7. Morris, D.R. 1995. Growth control of translation in mammalian cells. Prog. Nucleic Acids Res. Mol. Biol. 51:339-363.

8. Polunovsky, V.A., et al. 1996. Translational control of programmed cell death: eukaryotic translation initiation factor 4E blocks apoptosis in growth-factor-restricted fibroblasts with physiologically expressed or deregulated Myc. Mol. Cell. Biol. 16:6573-6581.

9. Marissen, W.E., and Lloyd, R.E. 1998. Eukaryotic translation initiation factor $4 \mathrm{G}$ is targeted for proteolytic cleavage by caspase 3 during inhibition of translation in apoptotic cells. Mol. Cell. Biol. 18:7565-7574.

10. Gil, J., Alcami, J., and Esteban, M. 1999. Induction of apoptosis by doublestranded-RNA-dependent protein kinase (PKR) involves the alpha subunit of eukaryotic translation initiation factor 2 and NF-kappaB. Mol. Cell. Biol. 19:4653-4663.

11. Merrick, W.C., and Hershey, J.W.B. 1996. The pathway and mechanism of eukaryotic protein synthesis. In Translational control. J.W.B. Hershey, M.B. Mathews, and N. Sonenberg, editors. Cold Spring Harbor Laboratory Press. Cold Spring Harbor, New York, USA. 31-69.

12. Shatkin, A.J. 1985. mRNA cap binding proteins: essential factors for initiation translation. Cell. 40:223-224.

13. Sonenberg, N., Morgan, M.A., Merrick, W.C., and Shatkin, A.J. 1978. A polypeptide in eukaryotic initiation factors that crosslinks specifically to the 5'-terminal cap in mRNA. Proc. Natl. Acad. Sci. USA. 75:4843-4847.

14. Joshi-Barve, S., Rychlik, W., and Rhoads, R.E. 1990. Alteration of the major phosphorylation site of eukaryotic protein synthesis initiation factor $4 \mathrm{E}$ prevents its association with the $48 \mathrm{~S}$ initiation complex. J. Biol. Chem 265:2979-2983

15. Morley, S.J., Dever, T.E., Etchison, D., and Traugh, J.A. 1991. Phosphorylation of eIF4F by protein kinase C or multipotential $\mathrm{S} 6$ kinase stimulates protein synthesis at initiation. J. Biol. Chem. 266:4669-4672.

16. Lazaris-Karatzas, A., Montine, K.S., and Sonenberg, N. 1990. Malignant transformation by a eukarotic initiation factor subunits that binds to mRNA 5' cap. Nature. 345:544-547.

17. Lin, T.-A., et al. 1994. PHAS-I as a link between mitogen-activated protein kinase and translation initiation. Science. 266:653-656.

18. Pause, A., et al. 1994. Insulin-dependent stimulation of protein synthesis by phosphorylation of a regulator of 5'-cap function. Nature. 371:762-767.

19. Hu, C., Pang, S., Kong, X., Velleca, M., and Lawrence, J.C., Jr. 1994. Molecular cloning and tissue distribution of PHAS-I, an intracellular target for insulin and growth factors. Proc. Natl. Acad. Sci. USA. 91:3730-3734.

20. Haghighat, A., Mader, S., Pause, A., and Sonenberg, N. 1995. Repression of cap-dependent translation by 4E-binding protein 1: competition with p220 for binding to eukaryotic initiation factor-4E. EMBO J. 14:5701-5709.

21. Kimball, S.R. 1999. Eukaryotic initiation factor eIF2. Int.J. Biochem. Cell Biol. 31:25-29.

22. De Haro, C., Mendez, R., and Santoyo, J. 1996. The eIF-2alpha kinases and the control of protein synthesis. FASEBJ. 10:1378-1387.

23. Hovanessian, A.G. 1993. dsRNA-activated protein kinase (PKR): antiproliferative antiviral and antitumoral functions. Semin. Virol. 4:237-245.

24. Jedlicka, P., and Panniers, R. 1991. Mechanism of activation of protein synthesis initiation in mitogen-stimulated $\mathrm{T}$ lymphocytes. J. Biol. Chem. 266:15663-15669.

25. Cohen, R.B., Boal, T.R., and Safer, B. 1990. Increased eIF-2 alpha expression in mitogen-activated primary T lymphocytes. EMBOJ. 9:3831-3837.

26. Mao, X., et al. 1992. Regulation of translation initiation factor gene expression during human T cell activation. J. Biol. Chem. 267:20444-20450.

27. Boal, T.R., et al. 1993. Regulation of eukaryotic translation initiation factor expression during T-cell activation. Biochim. Biophys. Acta. 1176:257-264.

28. Tan, E.M., et al. 1982. The 1982 revised criteria for the classification of systemic lupus erythematosus. Arthritis Rheum. 25:1271-1277.

29. Arnett, F.C., et al. 1988. The American Rheumatism Association 1987 revised criteria for the classification of rheumatoid arthritis. Arthritis Rheum. 31:315-324.

30. Liang, M.H., Socher, S.A., Larson, M.G., and Schur, P.H. 1989. Reliability and validity of six systems for the clinical assessment of disease activity in systemic lupus erythematosus. Arthritis Rheum. 32:1107-1118.

31. Bombardier, C., Gladman, D.D., Urowitz, M.B., Caron, D., and Chang, C.H. 1992. Derivation of the SLEDAI. A disease activity index for lupus patients. The Committee on Prognosis Studies in SLE. Arthritis Rheum. 35:630-640.

32. Ramakrishnan, S., and Houston, L.L. 1984. Inhibition of human acute lymphoblastic leukemia cells by immunotoxins: potentiation by chloroquine. Science. 223:58-61.
33. Kerkhoff, C., Gehring, L., Habben, K., Resch, K., and Kaever, V. 1997. The mitogen-induced lysophospholipid: acyl-coA acyltransferase (LAT) expression in human T-lymphocytes is diminished by hydrocortisone. Biochem. Biophys. Res. Commun. 237:632-638.

34. Strahler, J.R., Kuick, R., and Hanash, S.M. 1989. Two-dimensional polyacrylamide gel electrophoresis of proteins. In Protein structure: a practical approach. T.E. Creighton, editor. IRL Press. Oxford, United Kingdom. $65-92$.

35. Beretta, L., et al. 1998. Differential regulation of translation and eIF4E phosphorylation during human thymocyte maturation. J. Immunol. 160:3269-3273.

36. Farrugia, J., and Cann, A.J. 1999. Internally controlled quantitative assays for PKR mRNA and protein from liver biopsies and other finite clinical samples. J. Immunol. Methods. 228:59-68.

37. Beretta, L., Gingras, A.C., Svitkin, Y., Hall, M.N., and Sonenberg, N. 1996. Rapamycin blocks the phosphorylation of 4E-BP1 and inhibits cap-dependent initiation of translation. EMBO J. 15:658-664.

38. Clemens, M.J., Bushell, M., and Morley, S.J. 1998. Degradation of eukaryotic polypeptide chain initiation factor (eIF) $4 \mathrm{G}$ in response to induction of apoptosis in human lymphoma cell lines. Oncogene. 17:2921-2931.

39. Garcia-Sanz, J.A., Mikulits, W., Livingstone, A., Lefkovits, I., and Mullner, E.W. 1998. Translational control: a general mechanism for gene regulation during T cell activation. FASEBJ. 12:299-306.

40. Koromilas, A.E., Roy, S., Barber, G.N., Katze, M., and Sonenberg, N. 1992. Malignant transformation by a mutant of the IFN-inducible dsRNAdependent protein kinase. Science. 257:5041-5044.

41. Chong, K.L., et al. 1992. Human p68 kinase (PKR) exhibits growth suppression in yeast and homology to the translational regulator GCN2. EMBOJ. 11:1553-1562.

42. Clemens, M.J., and Elia, A. 1997. The double stranded RNA-dependent protein kinase PKR: structure and function. J. Interferon Cytokine Res. 17:503-524.

43. Jagus, R., Joshi, B., and Barber, G.N. 1999. PKR, apoptosis and cancer. Int.J. Biochem. Cell Biol. 31:123-138.

44. Kaufman, R.J., and Srivasyava, S.P. 1996. PKR: a general transducer of the cellular stress response leading to apoptosis. In Translational control. J.W.B. Hershey, M.B. Mathews, and N. Sonenberg, editors. Cold Spring Harbor Laboratory Press. Cold Spring Harbor, New York, USA.

45. Lee, S.B., and Esteban, M. 1994. The interferon-induced double-stranded RNA-activated protein kinase induces apoptosis. Virology. 199:491-496.

46. Donze, O., Dostie, J., and Sonenberg, N. 1999. Regulatable expression of the interferon-induced double-stranded RNA dependent protein kinase PKR induces apoptosis and Fas receptor expression. Virology. 256:322-329.

47. Yeung, M.C., Liu, J., and Lau, A.S. 1996. An essential role for the interferoninducible, dsRNA-activated protein kinase, PKR, in the tumor necrosis factor-induced apoptosis in U937 cells. Proc. Natl. Acad. Sci. USA. 93:12451-12455

48. Der, S.D., Yang, Y.L., Weissman, C., and Williams, B.R. 1997. A dsRNA-activated protein kinase-dependent pathway mediating stress-induced apoptosis. Proc. Natl. Acad. Sci. USA. 94:3279-3283.

49. Lee, S.B., Rodriguez, D., Rodriguez,J.R., and Esteban, M. 1997. The apoptosis pathway triggered by the interferon-induced protein kinase, $\mathrm{PKR}$ requires the third basic domain, initiates upstream of Bcl-2, and involves ICE-like proteases. Virology. 231:81-88.

50. Srivastava, S.P., Kumar, K.U., and Kaufman, R.J. 1998. Phosphorylation of eIF2 mediates apoptosis in response to activation of PKR. J. Biol. Chem. 273:2416-2423.

51. Balachandran, S., et al. 1998. Activation of the dsRNA-dependent protein kinase, PKR, induces apoptosis through FADD-mediated death signaling. EMBO J. 17:6888-6902.

52. Papo, T., et al. 1998. Apoptosis and expression of soluble Fas mRNA in systemic lupus erythematosus. Lupus. 7:455-561.

53. Emlen, W., Niebur, J., and Kadera, R. 1994. Accelerated in vitro apoptosis of lymphocytes from patients with systemic lupus erythematosus. J. Immunol. 152:3685-3692

54. Georgescu, L., Vakkalanka, R.K., Elkon, K.B., and Crow, M.K. 1997. Interleukin-10 promotes activation-induced cell death of SLE lymphocytes mediated by Fas ligand. J. Clin. Invest. 100:2622-2633.

55. Kovacs, B., Liossis, S.N., Dennis, G.J., and Tsokos, G.C. 1997. Increased expression of functional Fas-ligand in activated T cells from patients with systemic lupus erythematosus. Autoimmunity. 25:213-221.

56. Kozak, M. 1991. An analysis of vertebrate mRNA sequences: intimations of translational control. J. Cell. Biol. 115:887-903.

57. Willis, A.E. 1999. Translational control of growth factor and proto-oncogene expression. Int. J. Biochem. Cell. Biol. 31:73-86.

58. Kruys, V., Marinx, O., Shaw, G., Deschamps, J., and Huez, G. 1989. Translational blockade imposed by cytokine-derived UA-rich sequences. Science. 245:852-855.

59. Garcia-Sanz, J.A., and Lenig, D. 1996. Translational control of interleukin2 messenger RNA as a molecular mechanism of T cell anergy. J. Exp. Med. 184:159-164. 